\title{
Muon-catalyzed fusion and annihilation energy generation will supersede non-sustainable $T+D$ nuclear fusion
}

\author{
Leif Holmlid*i(
}

\begin{abstract}
Background: Large-scale fusion reactors using hydrogen isotopes as fuel are under development at several places in the world. These types of fusion reactors use tritium as fuel for the $T+D$ reaction. However, tritium is not a sustainable fuel, since it likely will require fission reactors for its production, and since it is a dangerous material due to its radioactivity with main risks of release to the environment during tritium production, transport and refuelling operations. Thus, widespread use of fusion relying on tritium fuel should be avoided. At least two better methods for producing the nuclear energy needed in the world indeed already exist, using deuterium or ordinary hydrogen as fuel, and more methods need to be developed. It should be noted that the first experiments with sustained laser-driven fusion above break-even using deuterium as fuel were published already in 2015. Similar results for T+D fusion do not exist even after 60 years of development, which gives no confidence in this approach.

Main text: The well-known muon-induced fusion (often called muon-catalyzed fusion) can use non-radioactive deuterium as fuel. With the recent development of a high intensity muon source $\left(10^{13}\right.$ muons per laser shot) (patented), this method is technically and economically feasible today. Due to the low energy cost of producing muons at $<1 \mathrm{MeV}$ with this new source, the length of the so-called catalytic chain is unimportant. This removes the 60-yearold enigma, concerning the so-called alpha sticking process. The recently developed annihilation energy generation uses ordinary hydrogen in the form of ultradense hydrogen $\mathrm{H}(0)$ as fuel and is thus sustainable and has very high efficiency.

Conclusions: Muon-induced fusion is able to directly replace most combustion-based power stations in the world, giving sustainable and environmentally harmless power (primarily heat), in this way eliminating most $\mathrm{CO}_{2}$ emissions of human energy generation origin. Annihilation-based power generation has the potential to replace almost all other uses of fossil fuels within a few decades, also in mobile applications, including spaceflight, where it is the only method able to give relativistic rocket propulsion.
\end{abstract}

Keywords: Ultra-dense hydrogen, Nuclear fusion, Annihilation, Mesons, Muon-catalyzed fusion

\section{Background}

The experimental and fundamental physics of the quantum material ultra-dense hydrogen $\mathrm{H}(0)$ was described in a review in Physica Scripta) [1]. With measured

${ }^{*}$ Correspondence: holmlid@chem.gu.se

Department of Chemistry and Molecular Biology, University

of Gothenburg, 41296 Göteborg, Sweden interatomic distances of $2.3 \pm 0.1 \mathrm{pm}$ in the most commonly observed spin level $s=2$ (at low pressure and temperature in the laboratory $[1,2])$, this is the densest form of matter that exists on Earth and probably also in the Universe (at spin level $s=1$ it has the same density as white dwarf stars). This ultra-dense material has been extensively studied using laser-induced processes such as Coulomb explosions (CE), coupled to time-of-flight original author(s) and the source, provide a link to the Creative Commons licence, and indicate if changes were made. The images or other third party material in this article are included in the article's Creative Commons licence, unless indicated otherwise in a credit line to the material. If material is not included in the article's Creative Commons licence and your intended use is not permitted by statutory regulation or exceeds the permitted use, you will need to obtain permission directly from the copyright holder. To view a copy of this licence, visit http://creativecommons.org/licenses/by/4.0/. The Creative Commons Public Domain Dedication waiver (http://creativeco mmons.org/publicdomain/zero/1.0/) applies to the data made available in this article, unless otherwise stated in a credit line to the data. 
(TOF) and time-of-flight mass spectrometry (TOF-MS) analysis [2] of its molecular fragments, but also using rotational emission spectroscopy $[1,3,4]$ and nuclear processes. Rotational spectroscopy gives a precision of the interatomic distances in the femtometer range. The CE experiments observe molecular fragments with up to $2.5 \mathrm{keV} \mathrm{u}^{-1}$ energy without nuclear processes [5].

Particles with kinetic energy in the $\mathrm{MeV}$ range are easily released by nuclear processes in $\mathrm{H}(0)$ using $<0.4 \mathrm{~J}$ laser pulses $[1,6,7]$. Clear signs of $\mathrm{D}+\mathrm{D}$ fusion such as ${ }^{4} \mathrm{He}$ and ${ }^{3} \mathrm{He}$ ions have been observed [8]. Heat generation above break-even from nuclear fusion processes was reported in 2015 for the first time ever for $\mathrm{D}+\mathrm{D}$ fusion [9]. The $\mathrm{MeV}$ particle (meson) signal from laser induction is so large, $10^{13}$ particles per laser shot [10] that it can be measured with a fast oscilloscope (without pre-amplifiers) directly connected to a metal collector. The decaying signals after the laser pulse agree accurately with kaon (charged and neutral) and charged pion lifetimes $[1,10-13]$. The muon lifetimes have also been confirmed accurately [14]. These fast particles can be observed at distances up to $2 \mathrm{~m}$ in a vacuum giving good time resolution $[6,7,15,16]$. The particle velocities measured by direct timing and by decay-time dilation correspond to up to $500 \mathrm{MeV} \mathrm{u}^{-1}[10,11,17]$, and are relativistic. Using two [9] and three [15] collectors in line, it is confirmed that the fast particles have mass. Magnetic deflection studies confirm that the mass of the charged particles is less than $1 \mu$, thus mesons and muons, and that many of the initially formed particles are neutral [18] thus neutral kaons. Measurements with current coils show also that many of the relativistic particles are charged [12, 16, 17]. The generation of muons from the meson decay is further confirmed by accurate measurement of the decay time for the muons [14] and also by detecting neutrons from muon-induced fusion and muon capture [19].

\section{Nuclear energy}

\section{Annihilation processes}

The nuclear processes observed in $\mathrm{H}(0)$ to give meson ejection take place in small molecules $\mathrm{H}_{3}(0)$ and $\mathrm{H}_{4}(0)$ $[12,20]$. The muons formed from the decay of the kaons and pions have kinetic energies $>100 \mathrm{MeV} \mathrm{u}^{-1}[15,16$, 18]. The processes observed in $\mathrm{D}(0)$ are not primarily $\mathrm{D}+\mathrm{D}$ fusion processes, even if such fusion processes also exist in this system [8]. Instead, two baryons form three light meson pairs (kaons and pions) [21-24]. Such a process is energetically allowed and gives a large excess kinetic energy to the particles formed. The kinetic energies of the kaons and pions have been measured from their relativistically dilated decay times [11]. The masses of the particles formed and their kinetic energies agree within a few $\mathrm{MeV}$ with baryon + anti-baryon annihilation (see the Appendix).

\section{Fission processes}

For the future of energy generation, fission processes using $U$ or Th are believed to soon be obsolete, not only due to the considerable risks for accidents with their operation (for example, the Three-Mile Island, Chernobyl and Fukushima reactor accidents) but also due to the problems with radioactive waste products and the costs and risks associated with the storage of such radioactive waste for many thousand years which are required despite the research and development done in this field [44], also by the organization IAEA.

\section{Fusion processes}

Fusion processes based on $\mathrm{T}+\mathrm{D}$ fusion reactions in the form of magnetic confinement (such as the ITER research facility and other tokamaks) have attracted large interest and large government funding around the world. The possibility of technological and commercial success with this large-scale advanced technology can still not be estimated reliably after 60 years of development. In addition, laser-induced ICF (inertial confinement fusion) setups such as the world's largest laser (the National Ignition Facility (NIF) at Lawrence Livermore, California, USA) has required large investments and support, so far without much success $[25,26]$. (However, the NIF facility may anyway have been built mainly for weapons research.) Besides all the technical and scientific problems surrounding these two main trends in developing fusion power, there are more basic problems related to their fuel which make these large-scale fusion methods non-sustainable. Both methods are intended to use $\mathrm{T}+\mathrm{D}$ fusion, since this is the only hydrogen fusion reaction believed to work under the conditions attainable in such reactors (it has the lowest ignition temperature). For example D+D fusion cannot be used.

\section{Tritium as fusion fuel}

However, the fuel tritium does not exist in nature, and it may need to be produced in fission (uranium) reactors and be transported to the fusion reactor sites, or produced in separate facilities on-site [27, 28]. This clearly indicates that fusion methods using DT fuel are not more sustainable than fission. Large-scale breeding of tritium from $\mathrm{Li}$ (breeding blankets) in Tokamaks is not yet proved [27] and is probably not operational for a long 
time. Besides this, laser based ICF has no such option. Breeding from D by muon-induced fusion is much simpler (see further below) and is now possible due to the availability and low cost of muons from the new patented muon source [29].

The other problem with tritium is that it is radioactive and accidents with leakage to the atmosphere are likely to take place. In fact, the large-scale use of tritium is questionable, since tritium is a radioactive gas which is difficult to detect. It should be observed that tritium emits beta radiation (electrons) with quite low energy, at a maximum of $18.6 \mathrm{keV}$. This means that it cannot be detected by standard radiation instruments such as Geiger counters (GM tubes), due to the windows necessary in such devices. Thus, it is not easy to detect a leakage of tritium to air from any type of device. Leakage of tritium to the atmosphere will give enhanced radioactivity in breathing air, finally in the form of water which is easily absorbed in lungs and which gives radioactive damage and risk for cancer [30]. (As given in various safety data sheets SDS: GHS Signal Word: Danger. Exposure Routes: ingestion, inhalation, puncture, wound, skin contamination absorption). Ordinary undamaged skin is stated to not be penetrated by the beta radiation from tritium [31]. No such barriers exist in the lungs, so the tissue in lungs will be damaged by beta radiation from tritium.

With stringent and costly measures at the fusion reactor sites, the tritium release to the environment may become quite well controlled, but with a large number of fusion reactors (for example comparable to the number of fission reactors today) the tritium leakage to the environment will be substantial. Even in existing fission reactors, tritium emission to the atmosphere takes place which is a serious problem [30]. It is also clear that the largest risks of tritium emission in $\mathrm{D}+\mathrm{T}$ fusion energy production are during transport, maintenance, and repair as in all handling of dangerous chemicals and especially during fuel filling and refilling. A gas handling system of this size can never be perfect. This is one obvious reason why we still do not have a large hydrogen-based energy sector. The problems with tritium are of course much more severe than with ordinary hydrogen.

\section{Fusion accidents}

Another problem with high temperature $\mathrm{D}+\mathrm{T}$ fusion is of course the risk of explosive processes in the fusion reactor. Plasma based methods have such risks, since the fusion process is thermonuclear and it may support itself in an ignited mode. Of course, using picomol quantities of the fuel, the risks are smaller but the usefulness for large-scale energy generation also disappears. Other methods of fusion which do not use plasmas (such as muon-induced fusion) cannot give any explosive processes and are intrinsically much safer. Explosions in plasma based fusion devices can be dangerous and devastating. Future experience from accidents will of course give a better background.

\section{Sustainable nuclear fusion}

Thus, it is argued here that a sustainable nuclear fusion process must use deuterium or protium as hydrogen fuels, or possibly other more complex processes for example based on boron [32]. Suitable sustainable hydrogen nuclear reaction methods do exist. We will describe and discuss two of them below under the headings "muon-induced fusion" and "annihilation". Much more research on new nuclear energy production is needed, since it seems that $\mathrm{D}+\mathrm{T}$ fusion gives more problems than society and environment can accept.

\section{Energy efficiency of hydrogen nuclear processes}

One central aspect which is of great interest but often forgotten is the efficiency of the nuclear process in the fuel, which may be characterized by the fraction of the two fuel nuclei masses which is converted to energy. Such data are given in Table 1. While $\mathrm{D}+\mathrm{T}$ fusion has an efficiency of only $0.3 \%$, annihilation has a measured efficiency of approximately $46 \%$, thus more than 100 times higher [33]. This means that no refueling during the lifetime of the device will be necessary for many applications. From Table 1, it is seen that $\mathrm{D}+\mathrm{D}$ fusion by muon induced (catalyzed) fusion should be the primary choice of a sustainable fusion process at present. This is probably the first and also only generation of fusion reactors which needs to exist, since the next generation of nuclear power generation after that is likely to be annihilation power using ordinary hydrogen in the form of $\mathrm{H}(0)$ as fuel.

\section{Muon-induced fusion}

The central reactions in muon-induced fusion $\mathrm{D}+\mathrm{D}$ in $D_{2}$ gas with energy out given for each step are $[10,34]$

$$
\begin{aligned}
& \mathrm{dde}^{+}+\mu^{-} \rightarrow \mathrm{dd} \mu^{+}+\mathrm{e}^{-} \\
& \mathrm{dd} \mu^{+} \rightarrow{ }^{3} \mathrm{He}^{2+}+\mathrm{n}+\mu^{-} \quad 3.3 \mathrm{MeV}
\end{aligned}
$$


Table 1 Characteristics of different hydrogen-based nuclear reactions for energy production

\begin{tabular}{|c|c|c|c|c|c|c|}
\hline Fuel reaction & Method & Reactor type & $\begin{array}{l}\text { Power Range } \\
\text { (thermal or } \\
\text { electricity as } \\
\text { indicated) }\end{array}$ & Efficiency (\%) & $\begin{array}{l}\text { Sustained } \\
\text { over-break- } \\
\text { even operation } \\
\text { demonstrated }\end{array}$ & Commercial start \\
\hline $\mathrm{T}+\mathrm{D}$ & Plasma & $\begin{array}{l}\text { Magnetic or inertial } \\
\text { confinement }\end{array}$ & $\mathrm{GW}_{\mathrm{el}}$ ? & $18 / 4500=0.3 \%$ & -- & Much later than 2030? \\
\hline $\mathrm{T}+\mathrm{D}$ & $\begin{array}{l}\text { Muon induced } \\
\text { fusion }\end{array}$ & Tube reactor & $\mathrm{MW}_{\text {th }}$ & $18 / 4500=0.3 \%$ & - & 2023 \\
\hline$D+D \ldots T+D$ & $\begin{array}{l}\text { Muon induced } \\
\text { fusion }\end{array}$ & $\begin{array}{l}\text { Tube or planar } \\
\text { reactor }\end{array}$ & $15 \mathrm{~kW}_{\mathrm{th}} \ldots \mathrm{MW}_{\mathrm{th}}$ & $4 / 3600=0.1 \% \ldots$ & partial power 2015 & 2023 \\
\hline$D+D$ & Annihilation & Planar reactor & $200 \mathrm{~kW}_{\mathrm{th}}-\mathrm{MW}$ & $10-50 \%$ estimated & partial power 2015 & 2023 est \\
\hline$D+D$ & Plasma & $\begin{array}{l}\text { Magnetic or inertial } \\
\text { confinement }\end{array}$ & - & $4 / 3600=0.1 \ldots \%$ & - & Never? \\
\hline$p+D \ldots D+D$ & $\begin{array}{l}\text { Muon induced } \\
\text { fusion }\end{array}$ & Tube reactor & $<<20 \mathrm{~kW}_{\mathrm{th}} ?$ & $5.5 / 2700=0.2 \%$ & & Never? \\
\hline$p+p$ & Annihilation & Planar reactor & $200 \mathrm{~kW}_{\mathrm{th}}-\mathrm{MW}$ & $10-50 \%$ est & 2021 & 2023 est \\
\hline$p+p, D+D$ & Annihilation & mechanical & $\mathrm{kW}_{\mathrm{el}}-\mathrm{MW}_{\mathrm{el}}$ & $10-50 \%$ est & & 2030 est \\
\hline
\end{tabular}

Est. means estimated. ... means that the fuel composition changes over time in a closed reactor

$$
\begin{aligned}
& \mathrm{dd} \mu^{+} \rightarrow{ }^{3} \mathrm{He} \mu^{+}+\mathrm{n} \quad 3.3 \mathrm{MeV} \\
& \mathrm{dd} \mu^{+} \rightarrow \mathrm{T}^{+}+\mathrm{p}^{+}+\mu^{-} \quad 4.0 \mathrm{MeV} \\
& \mathrm{dd} \mu^{+} \rightarrow \mathrm{T} \mu+\mathrm{p}^{+} \quad 4.0 \mathrm{MeV}
\end{aligned}
$$

A similar reaction scheme also exists for $\mathrm{T}+\mathrm{D}$ muon induced (catalyzed) fusion [10]. Reaction (1) is the step, where a muon replaces an electron in the $\mathrm{D}_{2}{ }^{+}$ion inside a $D_{2}$ molecule. This gives a shorter $d-d$ bond distance in approximate proportion to the ratio of the masses of the muon and the electron, thus $105.7 \mathrm{MeV} / 0.511 \mathrm{MeV}=207$ times shorter distance. Thus, instead of the interatomic distance of $106 \mathrm{pm}$ in normal (electron bound) $\mathrm{D}_{2}{ }^{+}$, the $\mathrm{d}-\mathrm{d}$ distance in $(\mathrm{dd} \mu)^{+}$is expected to be $0.51 \mathrm{pm}$. In reactions (2) and (3), the muons are released after the DD fusion which means that the muons can take part in several such reactions as Eq. (1) before they decay with lifetime $2.20 \mu \mathrm{s}$. This feature is the reason for the name muon-catalyzed fusion with the muon as the non-consumed catalyst. The number of such catalytic steps initiated by one muon has been an important point for research and discussion since the first observations of muon-induced fusion in 1957 [35]. However, with the recent development of intense muon generators giving cheap muons [29] this point is no longer of great concern, since the process is both technically and economically feasible with a small number of catalytic steps. The muon-induced and muon-catalyzed fusion processes have been studied by large groups since 1957 with impressive results [34, 36, 37]. Reactors of this type were recently analyzed carefully in a Ph.D. thesis in London 2018 [38] by R.S. Kelly. The energetics of the nuclear reactions using the existing patented muon generator have been analyzed [10]. The function of the muon generator was proved further by the observation of neutrons from fusion in $D_{2}$ gas [19] as in Eqs. (2) and (2a).

\section{Muon production}

Since the energy cost of producing muons by accelerators has been very large, of the order of $\mathrm{GeV}$, the old problem since the 1950s has been how many pairwise fusion reactions each muon can induce (or so-called catalyze) before decaying within its decay life-time of $2.20 \mu \mathrm{s}$. This problem is enhanced by the reaction (2a) above, where the muon sticks to the He nucleus and the (so-called catalytic) chain is broken. In reality, this sticking to the $\alpha$ particle is so strong that a chain length of 180-200 steps is the maximum expected and reported [34, 38]. However, with the new muon generator, of the order of $10^{13}$ muons are formed for each laser pulse of $0.4 \mathrm{~J}$. This means an energy cost of $0.4 / 1.6 \times 10^{-19} \mathrm{eV}$ per pulse or $0.25 \mathrm{MeV}$ per muon, a decrease by a factor of more than $10^{3}$ relative to accelerator technology. This means that the muons are not expensive to use or lose. The processes used 
for their production are the same as for the annihilation described below: kaon and pion formation from baryon annihilation giving muons by meson decay. The patent description [29] is complete and can be repeated easily by anyone knowledgeable in the fields of vacuum and chemical catalysis. A complete description of the science and technology behind the production of ultradense hydrogen [1] was also recently published [39]. The importance of carbon surfaces for the formation of Rydberg species at surfaces was known long before 1998, when the key reference [40] was published. Another relevant review is found in [41]. The properties of $\mathrm{H}(0)$ are in many respects similar to those of ordinary RM [41] but many differences also exist. The description of RM in [43] is valid mainly for large $l$ values thus for the third and largest length scale of RM $[1,45]$ with very loose cluster structures, while the nuclear processes only exist in the first and shortest length scale $\mathrm{H}(0)$ with very closely bound molecules. The muon generation capacity has been measured in numerous experiments with constant results. No impurity [43] problems have been observed.

\section{Tritium in muon-induced fusion}

The most important aspect of muon-induced fusion is that it can use deuterium as fuel. As seen in reaction (3) this fusion process gives tritium as one product. Tritium can then fuse with deuterium by the muoninduced process, giving a more energetic reaction step [10]. This means that the composition of the fuel in the reactor and thus also the energy output changes with time, giving increased energy output when the fuel becomes enriched in tritium [10, 38]. This enrichment of tritium may take years of running the muoninduced reactor. This tritium does not need to be handled openly, and the risk of leakage to the atmosphere is small. It is envisaged for commercial muoninduced reactors that the central reactor gas container is exchanged when the high-pressure vessel needs service (inspection, testing) so that the gas in the reactor is exchanged to a lower tritium content after a period of a few years. In this way, a safer method of tritium production also exists, cutting the ties from fission to fusion reactors and thus making fission reactors obsolete even if large-scale fusion $\mathrm{T}+\mathrm{D}$ has been developed and fills a demand, e.g., for large-scale electricity generation.

In the same way, it is also possible to produce deuterium from protium in a muon-induced fusion reactor.
However, this reaction is probably too slow to be useful for energy production (giving too low power) [10, $36,37]$. Anyway, ordinary hydrogen is possible to use as a fuel in the annihilation energy generation process described below.

\section{Annihilation}

The most important property of a nuclear process for energy generation is of course that it is possible to reach break-even, thus that more energy can be generated by the process than what is required to start and maintain it. The first such report on break-even in fusion was published in 2015 [9] in a system using ultra-dense deuterium $\mathrm{D}(0)$ as fuel. No similar results exist for $\mathrm{D}+\mathrm{T}$ fusion. (The so called scientific breakeven in NIF [25] is a special definition of break-even which is of limited practical interest). The nuclear process taking place in $\mathrm{D}(0)$ in Ref. [9] was mixed as can be concluded now after 5 further years of research, with contributions from both muon-induced fusion and annihilation energy generation. At the time of that experiment, the annihilation process and the muon generation had not yet been identified, so the process was then thought to be laser-induced ICF using the $\mathrm{D}+\mathrm{D}$ reaction which was, however, considered to be impossible.

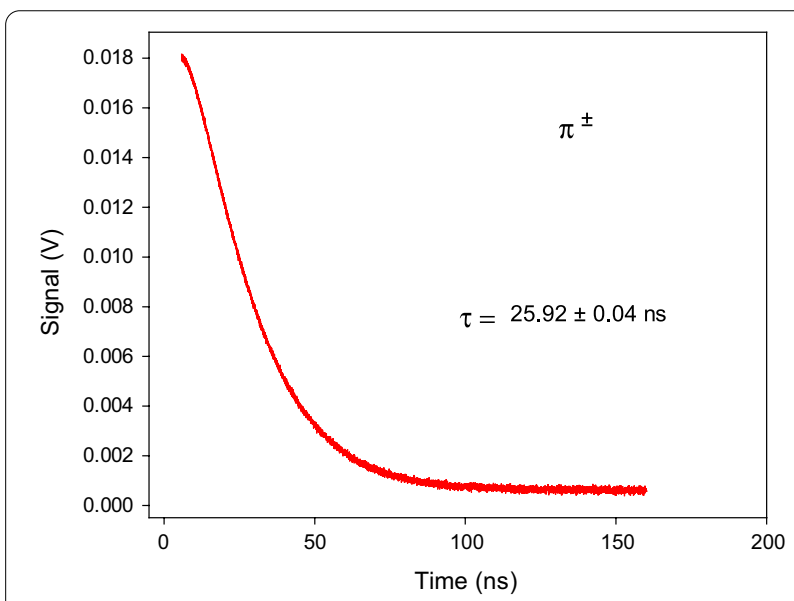

Fig. 1 Time variation of meson signal from an annihilation experiment. $\mathrm{D}(0)$ on laser target, $50 \mathrm{mbar}_{2}$ gas in $2 \mathrm{~m}$ long tubular vertical chamber. The decay time is obtained by a converged non-linear least squares 2-parameter fit in the program SigmaPlot 14 using 560 measured points for the fit. The time constant value found agrees within $0.4 \%$ with the accepted decay time for a stationary charged pion, at $26.033 \mathrm{~ns}$ [22] 


\section{Meson generation}

The annihilation process generates fast mesons, especially charged and neutral kaons at typical energies of $100 \mathrm{MeV}$ or $200 \mathrm{MeV} \mathrm{u}^{-1}[11,13,17]$. From this high kinetic energy, it is estimated that $600-1200 \mathrm{MeV}$ kinetic energy is generated per pair of nucleons, thus $30-60 \%$ of the nucleon pair mass is converted to useful kinetic energy. The mass of the kaons is also transferred to lighter particles and to kinetic energy by the kaon and subsequent pion decays, but this energy is partly deposited in hard-to-use neutrinos and gammas. For one typical decay pattern which was analyzed in detail, $46 \%$ of the mass of the initially reacting nucleon pair is converted to useful energy with the main loss to neutrinos [11]. (See further in the Appendix). A conservative estimate is used in Table 1 as $10-50 \%$ to thermal or kinetic (mechanical) energy. Since the technology for transfer to mechanical energy is not yet fully developed, this value is just an estimate. The first description of a rocket drive for relativistic interstellar travel was recently published [13], using the momentum of the kaons generated by the annihilation process for the rocket drive. This constitutes a first step in the development of entirely new technology to utilize the annihilation energy process.

As an example of the general results on mesons, a simple meson-decay signal from laser-induced annihilation in $D(0)$ is shown in Fig. 1. The results agree with the decay of stationary charged pions [21-24]. This means that there is no time dilation for these pions and their observed lifetime agrees with standard values [24], in this case within $0.4 \%$. In this experiment, a pair of magnets was used to deflect and separate the particles with different charge, and the difference between the two deflected fluxes was measured including their sign. In this way, the signal due to neutral kaons was suppressed. The lightest and slowest mesons thus the charged pions should be the easiest magnetically separated particles, as observed. The good agreement with the accepted decay time for pions $\pi^{ \pm}$proves that high energies and large particle masses exist in the laser-induced annihilation process. Results on charged and neutral kaons are also found in other references [10, 12, 15, 16, 18]. See further in the Appendix.

\section{Conclusions}

It is concluded that sustainability concerns will prevent the use of nuclear fusion using the $\mathrm{T}+\mathrm{D}$ reaction for energy production due to its use of tritium as fuel. The only sustainable hydrogen fusion method, muon-induced fusion uses deuterium as fuel, and the only nuclear energy production method that is so sustainable that it can use abundant ordinary hydrogen as fuel is annihilation energy production. In fact, there is no need for $\mathrm{T}+\mathrm{D}$ fusion for energy production, since these two sustainable methods already exist.

\section{Appendix: Mesons formed by annihilation in $\mathrm{H}(0)$ and their kinetic energies}

The experimental results on meson identification and decay from Ref. [11] are displayed in Table 2.

The annihilation energy conservation for proton + antiproton annihilation becomes, with kinetic energy in parentheses from Table 2:

$$
\begin{aligned}
& p+\bar{p} \rightarrow 2 K^{ \pm}(96 \mathrm{MeV})+2 \pi^{ \pm}(69 \mathrm{MeV})+2 \pi^{ \pm}(0 \mathrm{MeV}) \\
& \Rightarrow 2 \times 938-2 \times(494+96)-2 \times(140+69)-2 \times(140) \\
& =1876-1878=-2 \mathrm{MeV}
\end{aligned}
$$

The charged kaon pair may be replaced with a neutral kaon pair, either long-lived or short-lived pairs, since the neutral kaons are their own antiparticles.

\begin{tabular}{|c|c|c|c|c|c|c|}
\hline $\begin{array}{l}\text { Observed decay- } \\
\text { time (ns) }\end{array}$ & Particle & $\begin{array}{l}\text { Particle decay-time } \\
\text { (ns) }[24]\end{array}$ & Dilation factor & Velocity/c & Kinetic energy (MeV) & $\begin{array}{l}\text { Figures } \\
\text { and a few } \\
\text { References }\end{array}$ \\
\hline 13 (adjusted) & $K^{ \pm}$ & 12.38 & 1.05 & 0.305 & 29.4 & {$[12,13]$} \\
\hline $14.81 \pm 0.05$ & $K^{ \pm}$ & 12.38 & 1.196 & 0.549 & $95.7 \pm 2.0$ & [11] \\
\hline 26 (adjusted) & $\pi^{ \pm}$ & 26.033 & 1.0 & Low & Low & {$[1,10,12]$} \\
\hline $25.92 \pm 0.04$ & $\pi^{ \pm}$ & 26.033 & 1.0 & Low & Low & Figure 1 \\
\hline 39 (adjusted) & $\pi^{ \pm}$ & 26.033 & 1.5 & 0.745 & 68.9 & {$[42]$} \\
\hline $40.43 \pm 0.10$ & $\pi^{ \pm}$ & 26.033 & 1.555 & 0.766 & $76.7 \pm 0.5$ & [11] \\
\hline 52 (adjusted) & $\mathrm{K}_{\perp}^{0}$ & 51.16 & 1.016 & 0.18 & 16 & {$[1,13]$} \\
\hline $61.3 \pm 0.07$ & $K_{L}^{0}$ & 51.16 & 1.198 & 0.551 & $97.4 \pm 0.7$ & {$[11]$} \\
\hline
\end{tabular}
The experimental error limits from the particle kinetic

Table 2 Summary of previous results on meson decay time constants

The error limits are standard errors from converged non-linear least squares fits with two parameters (SigmaPlot 14). (adjusted) means manual adjustment of the rate constants for the best visual fit as in Ref. $[1,13]$ 
energies given in Table 2 will give an error larger than the difference $-2 \mathrm{MeV}$ indicated. The agreement in the energy matching is accurate within a few $\mathrm{MeV}$ or $0.2 \%$, showing that annihilation is the process giving the mesons (of course, no other real alternative exists even without this energy matching, since numerous mesons with high energy are formed).

\section{Acknowledgements}

This manuscript was posted on the In Review preprint server [46].

\section{Authors' contributions}

LH has contributed all aspects of the paper. The author read and approved the final manuscript.

\section{Funding}

Open access funding provided by University of Gothenburg. There was no special funding for this project.

\section{Availability of data and materials}

All data are available or cited in the paper.

\section{Declarations}

Ethical approval and consent to participate

Not applicable.

\section{Consent for publication}

Not applicable.

\section{Competing interests}

The author is co-owner of a company that works with development of annihilation energy generation and meson production, but there are no competing interests, since the sustainability problems with tritium as fusion fuel are known since long.

Received: 10 January 2021 Accepted: 8 February 2022

Published online: 22 February 2022

\section{References}

1. Holmlid L, Zeiner-Gundersen S (2019) Ultradense protium $p(0)$ and deuterium $\mathrm{D}(0)$ and their relation to ordinary Rydberg matter: a review. Phys Scr. https://doi.org/10.1088/1402-4896/ab1276

2. Holmlid L (2013) Laser-mass spectrometry study of ultra-dense protium $\mathrm{p}(-1)$ with variable time-of-flight energy and flight length. Int J Mass Spectrom 351:61-68. https://doi.org/10.1016/j.jims.2013.04.006

3. Holmlid L (2017) Emission spectroscopy of IR laser-induced processes in ultra-dense deuterium $\mathrm{D}(0)$ : rotational transitions with spin values $s=2$, 3 and 4. J Mol Struct 1130:829-836. https://doi.org/10.1016/j.molstruc 2016.10.091

4. Holmlid L (2018) Rotational emission spectroscopy in ultra-dense hydrogen $p(0)$ and $p_{x} D_{y}(0)$ : groups $p_{N}, p D_{2}, p_{2} D$ and $(p D)_{N}$. J Mol Struct 1173:567-573. https://doi.org/10.1016/j.molstruc.2018.06.116

5. Holmlid $L$ (2013) Excitation levels in ultra-dense hydrogen $p(-1)$ and $d(-1)$ clusters: structure of spin-based Rydberg Matter. Int J Mass Spectrom 352:1-8. https://doi.org/10.1016/j.ijms.2013.08.003

6. Holmlid L (2013) Two-collector timing of 3-14 MeV/u particles from laser-induced processes in ultra-dense deuterium. Int J Modern Phys E 22:1350089. https://doi.org/10.1142/S0218301313500894

7. Olofson F, Holmlid L (2014) Electron-positron pair production observed from laser-induced processes in ultra-dense deuterium D(-1). Laser Part Beams 32:537-548. https://doi.org/10.1017/50263034614000494

8. Olofson F, Holmlid L (2014) Time-of-flight of He ions from laser-induced processes in ultra-dense deuterium D(0). Int J Mass Spectrom 374:33-38. https://doi.org/10.1016/j.ijms.2014.10.004
9. Holmlid L (2015) Heat generation above break-even from laser-induced fusion in ultra-dense deuterium. AIP Adv 5:087129. https://doi.org/10. 1063/1.4928572

10. Holmlid L (2019) Existing source for muon-catalyzed nuclear fusion can give MW thermal fusion generator. Fusion Sci Technol 75(3):208-217. https://doi.org/10.1080/15361055.2018.1546090

11. Holmlid L Decay-times of pions and kaons formed by laser-induced nuclear processes in ultra-dense hydrogen $\mathrm{H}(0)$. Submitted

12. Holmlid L (2019) Laser-induced nuclear processes in ultra-dense hydrogen take place in small non-superfluid $\mathrm{H}_{\mathrm{N}}(0)$ clusters. J Cluster Sci 30(1):235-242. https://doi.org/10.1007/s10876-018-1480-5

13. Holmlid L, Zeiner-Gundersen S (2020) Future interstellar rockets may use laser-induced annihilation reactions for relativistic drive. Acta Astronaut 175:32-36. https://doi.org/10.1016/j.actaastro.2020.05.034

14. Holmlid L, Olafsson S (2019) Decay of muons generated by laser-induced processes in ultra-dense hydrogen. Heliyon 5(6):e01864. https://doi.org/ 10.1016/j.heliyon.2019.e01864

15. Holmlid L (2015) MeV particles in a decay chain process from laserinduced processes in ultra-dense deuterium D(0). Int J Modern Phys $\mathrm{E}$ 24:1550026. https://doi.org/10.1142/S0218301315500263

16. Holmlid L (2015) Nuclear particle decay in a multi-MeV beam ejected by pulsed-laser impact on ultra-dense hydrogen $\mathrm{H}(0)$. Int J Modern Phys $\mathrm{E}$ 24:1550080. https://doi.org/10.1142/S0218301315500809

17. Holmlid L (2021) Controlling the process of muon formation for muon-catalyzed fusion: method of non-destructive average muon sign detection. EPJ Techn Instrum 8:15. https://doi.org/10.1140/epjti/ s40485-021-00072-9

18. Holmlid $L$ (2017) Mesons from laser-induced processes in ultra-dense hydrogen H(0). PLoS ONE 12:e0169895. https://doi.org/10.1371/journal. Pone.0169895

19. Holmlid L (2018) Neutrons from muon-catalyzed fusion and from capture processes in an ultra-dense hydrogen $\mathrm{H}(0)$ generator. Fusion Sci Technol 74(3):219-228. https://doi.org/10.1080/15361055.2017.1421366

20. Holmlid L (2011) High-charge Coulomb explosions of clusters in ultradense deuterium D(-1). Int J Mass Spectrom 304:51-56. https://doi.org/ 10.1016/j.ijms.2011.04.001

21. Nordling C, Österman J (1988) Physics handbook. Studentlitteratur, Lund

22. Burcham WE, Jobes M (1995) Nuclear and particle physics. Pearson, Harlow

23. Kamal A (2014) Particle physics. Springer-Verlag, Berlin Heidelberg

24. Tanabashi M et al (2018) Particle data group. The review of particle physics. Phys Rev D 98:030001. http://pdg.lbl.gov

25. Hurricane O, Callahan D, Casey D et al (2014) Fuel gain exceeding unity in an inertially confined fusion implosion. Nature 506:343-348. https://doi. org/10.1038/nature13008

26. Holmlid L (2014) Ultra-dense hydrogen $\mathrm{H}(-1)$ as the cause of instabilities in laser compression-based nuclear fusion. J Fusion Energy 33:348-350. https://doi.org/10.1007/s10894-014-9681-x

27. Antunes R Tritium: a challenging fuel for fusion. https://www.euro-fusion. org/news/2017-3/tritium-a-challenging-fuel-for-fusion/ read 21-01-03.

28. Garcinuño B, Rapisarda D, Antunes R, Utili M, Fernández-Berceruelo I, Sanz J, Ibarra Á (2018) The tritium extraction and removal system for the DCLLDEMO fusion reactor. Nucl Fusion 58:095002

29. Holmlid. Apparatus for generating muons with intended use in a fusion reactor. Patent nr SE 539684 C 2.

30. Investigation of the Environmental Fate of Tritium in the Atmosphere, Part of the Tritium Studies Project INFO-0792, Published by the Canadian Nuclear Safety Commission (CNSC), 2009.

31. Fact Sheet Tritium, https://nuclearsafety.gc.ca/eng/pdfs/Fact_Sheets/ January-2013-Fact-Sheet-Tritium_e.pdf. Read 2020-07-09.

32. Hora H, Miley GH, Ghoranneviss M, Malekynia B, Azizic N, He X-T (2010) Fusion energy without radioactivity: laser ignition of solid hydrogenboron (11) fuel. Energy Environ Sci 3:479-486. https://doi.org/10.1039/ b904609g

33. Holmlid L (2021) Energy production by laser-induced annihilation in ultradense hydrogen $\mathrm{H}(0)$. Int J Hydrogen Energy 46:14592-14595. https://doi.org/10.1016/j.ijhydene.2021.01.212

34. Balin DV, Ganzha VA, Kozlov SM, Maev EM, Petrov GE, Soroka MA, Schapkin GN, Semenchuk GG, Trofimov VA, Vasiliev AA, Vorobyov AA, Voropaev NI, Petitjean C, Gartner B, Lauss B, Marton J, Zmeskalc J, Case T, Crowe KM, Kammel P, Hartmann FJ, Faifman MP (2011) High precision study of muon 
catalyzed fusion in D2 and HD gas. Phys Part Nuclei 42:185-214. https:// doi.org/10.1134/S106377961102002X

35. Alvarez LW et al (1957) Catalysis of nuclear reactions by $\mu$ mesons. Phys Rev 105:1127. https://doi.org/10.1103/PhysRev.105.1127

36. Filipowicz $\mathrm{M}$ et al (2008) Kinetics of muon catalyzed fusion processes in solid H/D mixture. Eur Pys J D 47:157. https://doi.org/10.1140/epjd/ e2008-00021-7

37. Friar JL et al (1991) Nuclear transition rates in $\mu$-catalyzed P-D fusion. Phys Rev Lett 66:1827. https://doi.org/10.1103/PhysRevLett.66.1827

38. Kelly RS (2018) Muon Catalyzed Fusion. An investigation of reactor design. Thesis, September 2018, Department of Physics, Imperial College London. https://doi.org/10.25560/68290

39. Holmlid L, Kotarba A, Stelmachowski P (2021) Production of ultra-dense hydrogen H(0): a novel nuclear fuel. Int J Hydrogen Energy 46:1846618480. https://doi.org/10.1016/j.ijhydene.2021.02.221

40. Holmlid L (1998) Complex kinetics of desorption and diffusion. Field reversal study of K excited-state desorption from graphite layer surfaces. J Phys Chem A 102:10636-10646. https://doi.org/10.1021/jp9823796

41. Holmlid L (2012) Experimental studies and observations of clusters of Rydberg matter and its extreme forms. J Cluster Sci 23:5-34. https://doi. org/10.1007/s10876-011-0417-z

42. Holmlid L (2016) Leptons from decay of mesons in the laser-induced particle pulse from ultra-dense protium $\mathrm{p}(0)$. Int J Modern Phys $\mathrm{E}$ 25:1650085. https://doi.org/10.1142/S0218301316500853

43. Ojovan MI (2012) Rydberg matter clusters: theory of interaction and sorption properties. J Clust Sci 23:35-46. https://doi.org/10.1007/ s10876-011-0410-6

44. Ojovan MI, Lee WE (2014) An introduction to nuclear waste immobilisation, 2nd edn. Elsevier, Amsterdam, p 362

45. Hirsch JE (2012) The origin of the Meissner effect in new and old superconductors. Phys Scr 85:035704. https://doi.org/10.1088/0031-8949/85/ 03/035704

46. Holmlid L (2021) Muon-catalyzed fusion and annihilation energy generation will supersede non-sustainable T+D nuclear fusion. https://doi.org/ 10.21203/rs.3.rs-148681/v1

\section{Publisher's Note}

Springer Nature remains neutral with regard to jurisdictional claims in published maps and institutional affiliations.

- fast, convenient online submission

- thorough peer review by experienced researchers in your field

- rapid publication on acceptance

- support for research data, including large and complex data types

- gold Open Access which fosters wider collaboration and increased citations

- maximum visibility for your research: over $100 \mathrm{M}$ website views per year

At BMC, research is always in progress.

Learn more biomedcentral.com/submissions 